DOI 10.37882/2223-2982.2021.04-2.40

\title{
ЕЩЕ РАЗ 0 «ВОССТАНИИ» ГОТОВ АЛАРИХА В 395 ГОДУ В КОНТЕКСТЕ ПРОТИВОСТОЯНИЯ СТИЛИХОНА И РУФИНА
}

\section{ONCE AGAIN TO THE "UPRISING" OF THE GOTHS OF ALARIC IN 395 IN THE CONTEXT OF THE CONFRONTATION BETWEEN STILICHO AND RUFINUS}

\section{S. Yartsev}

Summary: The article is devoted to the complex topic of the "uprising" of the Goths of Alaric on the territory of the Roman Empire in 395. Based on a thorough analysis of the sources, the author reviews these events in the context of the confrontation between Stilicho and Rufinus, the actual rulers of the West and East of the Roman Empire. The author believes that one of the main reasons for the conflict between the Romans and the Goths who were currently in Italy was the unexpected news for the barbarians about the brutal destruction of their homes in Thrace by the Huns. All this led to the need to revise the Gothic and Roman treaty and the demand of the barbarians to provide them with safer territories for settlement. However, Rufinus' new treaty with Alaric, authorizing the settlement of the Goths in the strategically important western province of Illyricum, triggered Stilicho's retaliatory campaign to the East against Alaric. It was the justification of this invasion and the attempt to hide its true causes that led to the appearance in the sources of horror of the Gothic "uprising", which in fact did not go beyond the violent withdrawal of food from the local population by the barbarians. Most likely, Stilicho set himself the goal of breaking this treaty, and returning Alaric to his command. Apparently, for Stilicho, this was the most effective way to force Constantinople to accept his claim to primacy over the entire Roman Empire.

Rufinus' subsequent attempt to oust Stilicho from the eastern part of the Roman Empire, forcing him to return the Eastern army to Constantinople, led to the plot and murder of the Praetorian prefect of the East. After the fall of Rufinus, Alaric again lost the post of master of the army, and it was decided to return his Goths back to Thrace under the command of the new regional master Gainas. According to the author, it was Gainas, by his subordination to the western Roman command and personally to Stilicho, who was supposed to ensure the establishment of the latter's control over all the armed forces of the empire, despite their division into the western and eastern armies. If successful, it would lead Stilicho to his ultimate goal of dominating the entire empire.

Keywords: Roman Empire, Goths, Alaric, Gainas, Stilicho, Rufinus, Eutropius.
Яриев Сергей Владимирович

Д.и.н., дочент, Тульский государственный педагогический университет им Л.Н.Толстого

s-yartsev@yandex.ru

Аннотация: Статья посвящена сложной теме «восстания» на территории Римской империи готов Алариха в 395 году. На основе тщательного анализа источников автор пересматривает данные события в контексте противостояния Стилихона и Руфина, фактических правителей Запада и Востока Римской империи того времени. Автор считает, что одной из главных причин конфликта римлян с находившимися в данный момент в Италии готами, явилось неожиданное для варваров известие 0 жестоком разорении гуннами их домов во Фракии. Все это вызвало необходимость заключения нового гото-римского договора, на фоне требований варваров предоставить им более безопасные территории для расселения. Однако, заключенный Руфином новый договор с Аларихом, разрешающий расселение готов в стратегически важной для Запада провинции Иллирик, вызвал негативную реакцию и ответный поход Стилихона на Восток против Алариха. Именно оправдание данного вторжения и попытка скрыть его истинные причины, привели к появлению в источниках ужасов готского «восстания», которое на самом деле не выходило за рамки насильственного отъема варварами продовольствия у местного населения. Скорее всего, Стилихон поставил себе цель разорвать данный договор, а Алариха вернуть под свое командование. Видимо для Стилихона это был наиболее действенный способ заставить Константинополь принять его притязание на главенство над всей Римской империей.

Последующая попытка Руфина вытеснить Стилихона с территории восточной части Римской империи, заставив его вернуть восточную армию в Константинополь, привела к заговору и убийству префекта претория Востока. После падения Руфина, Аларих вновь потерял пост магистра армии, а его готов решено было вернуть обратно во Фракию под командование нового регионального магистра Гайны. По мнению автора именно Гайна своим подчинением западному римскому командованию и лично Стилихону, должен был обеспечить установление контроля последнего над всеми вооруженными силами империи, несмотря на их разделение на западную и восточную армии. В случае успеха, это бы привело Стилихона к его главной цели - главенству над всей империей.

Ключевые слова: Римская империя, готы, Аларих, Гайна, Стилихон, Руфин, Евтропий.

р. 156-158; 32, s. 89-94]. Однако многие исследователи в своих работах не рассматривают готский мятеж в контексте всего комплекса взаимосвязанных событий данного периода римской истории. Особенно мало внимания, в этой связи уделяется противостоянию Стилихона 
и Руфина, которое, безусловно, оказало существенное влияние на многие стороны жизни в империи соответствующего времени. Даже в самых последних трудах на указанную тему [16; 17], авторы вновь продолжают акцентировать внимание на обстоятельствах, которые стали уже традиционными в работах по данной тематике: гибели нескольких тысяч готов в битве при Фригиде и обиде Алариха на отсутствие назначения его на высокую воинскую должность.

Тем не менее, очевидно, что одной из главных причин конфликта римлян с находившимися в данный момент в Италии готами, явилось неожиданное для варваров известие о жестоком разорении гуннами их домов во Фракии. Подозрение о причастности римлян к данному нашествию, вместе с некоторыми другими негативными факторами, по-видимому, и стали катализаторами готского мятежа. В ходе него Руфин даже лишил Алариха поста командующего, который он, как мы знаем, получил еще на этапе подготовки к походу в Италию, хотя и несколько позднее, чем Гайна, Саул и Бакурий (Zosim., IV, $57,2)$. Мнение, что готский рикс был назначен на командную должность только после битвы при Фригиде [13, с. $100,127]$, сомнительно, ведь император считал правильный выбор командиров «важнейшей задачей» именно этапа «приготовления к войне» (Zosim., IV, 57, 1-2). Римские знаки отличия, которыми был удостоен Аларих после указанной битвы (Socr., VII, 10), скорее всего, относились к традиционным в таких случаях наградам (венкам, копьям, флажкам, ожерельям, браслетам, фалерам и т.д. [8, с. 138-139]). В любом случае, лишившийся воинского поста Аларих, вместе со своими готами был отпущен Стилихоном в места своей постоянной дислокации. Таким образом, если главной целью Руфина являлся именно возврат готов на Восток (Zosim., V, 5, 4), ради которого он и затеял конфликт со снятием готского рикса с высокой командной должности, то надо признать, что это ему блестяще удалось.

Нам неизвестно точное количество воинов, которые уходили с Аларихом на Восток [13, с. 128]. Правда впоследствии к нему вполне могли присоединиться готы, жившие в империи по договору 382 года и не участвующие в походе Феодосия I против узурпатора. Дискуссия на этот счет, вряд ли уместна [12, с. 275; 13, с. 128]. Аларих не мог бросить свой народ и определенно должен был вначале появиться во Фракии, чтобы оценить степень ущерба гуннского нападения. Только после этого все готы под предводительством Алариха, оставили дунайские провинции, так как они уже не отвечали безопасности живших на их территории людей. Теперь главной целью варваров являлся Константинополь [3, с. 201], где на предстоящих переговорах с Руфином, должно было выполнено главное требование готов о предоставлении им новых земель для расселения. Тем более что в столи- це сейчас совсем не было войск и Руфин остро нуждающийся в преданной ему армии, должен был пойти на уступки варварам и даже вернуть воинскую должность магистра Алариху. Последнее было принципиальным требованием готского рикса, так как в этом случае, он мог гарантировать своему народу обеспечение продовольствием за счет государства [4, с. 466].

Драматическую картину нашествия готов на Константинополь, которую рисует нам крайне тенденциозный текст Клавдиана, конечно, нельзя воспринимать всерьез (Claud. In Rufin., II, 50-100). Разумеется, никто из варваров не собирался штурмовать Константинополь. Чрезмерное насилие по отношению к простым жителям, также было исключено, ведь в случае жестокого отношения к местному населению, Алариху было бы сложнее рассчитывать на удовлетворение своих требований Руфином. Конечно, здесь необходимо учитывать возникшие проблемы с продовольствием для готов в ходе их возвращения на Восток. По этой причине варвары действительно могли заниматься насильственной реквизиции продуктов питания у местного населения [3, с. 199]. Однако, смелый выход Руфина на переговоры к Алариху за стены города практически без охраны, да еще и в готской одежде (Claud. In Rufin., II, 75-85), однозначно свидетельствует, что кровавые ужасы варварского нашествия, которые рисует нам Клавдиан в своем произведении, должны остаться исключительно на его совести. В этой связи слова придворного западноримского поэта о всюду пылающем пожаре, которые не коснулись только поместий Руфина (Claud. In Rufin., II, 71), также могут являться ловким пропагандистским приемом, необходимым для максимального очернения образа префекта претория Востока. Истинная же реальность была такова, что Руфин, по всей вероятности, удовлетворил все требования Алариха и таким образом вернул Константинополю готов-федератов, отстояв свою независимость от Стилихона. Очевидно, это и являлось истинной причиной откровенной вражды последнего по отношению к Руфину.

Правда, исходя из дошедших до нас источников, определить территорию, выделенную готам по новому договору, совсем не просто. Упоминание в этой связи Греции у Марцеллина Комита, вызывает сомнения, так как в тексте хроники не исключена контаминация событий 395 г. и 396-397 гг., когда Эллада действительно была охвачена восстанием готов. Заметим, что такое смешение исторических фактов, наиболее отчетливо выражено у Зосима (Zosim., V, 5-7). На это сразу обращаешь внимание, по причине того, что Руфин у Марцеллина Комита изображается, также как и у Зосима в образе предателя, задумавшего «заговор против императора Аркадия», и изменника, побудившего «готского короля Алариха угрожать государству, тайно послав ему деньги и направив его в Грецию» (Marcell. Chron., 395). Конечно, из-за такого 
явного искажения исторических фактов, решить данную проблему с опорой на указанные источники, практически невозможно. Однако постараться определить новую готскую территорию, отчасти можно и другим способом. Например, если внимательно проанализировать некоторые особенности недавнего опыта варваров, расселившихся на землях империи. Исходя из этого, можно предположить, что готы, могли потребовать себе земли в диоцезе Иллирик, так как именно в этой части империи на территории Паннонии с 380 года, уже проживали варвары Алафея и Сафрака (lord. Get., 141). То, что они находились здесь в гораздо лучших условиях, вполне могло подвигнуть готов на требование своего расселения в аналогичной, условно комфортной среде. В пользу диоцеза Иллирик может свидетельствовать и хорошо известный страх Руфина перед Стилихоном. Именно он мог послужить причиной передислокации верных Константинополю готов в районы возможного пути следования западной армии, скорее всего, ближе к горным проходам, имеющим стратегическое значение для Италии. Исходя из последней причины, Стилихон, безусловно, сам хотел захватить Иллирик, с чем согласны многие исследователи [24, р. 195; 27, р. 74; 31, р. 28]. Точка зрения о том, что осознание важности этой провинции, пришло к Стилихону только позднее, выглядит неубедительно [21, р. 59-60]. То, что Клавдиан принципиально не концентрировал внимание на притязаниях Стилихона на данную область, легко объясняется, особой задачей придворного поэта, стремящегося изобразить своего патрона спасителем римского государства, а не захватчиком чужих земель.

Таким образом, Аларих, возможно получивший от Руфина высокое назначение magister militum per Illyricum, после Константинополя вместе со всеми готами стал продвигаться на новую территорию для расселения [3, с. 202]. Высокое назначение Алариха, подтверждается упомянутыми выплатами, которые были предусмотрены федератам за службу (Marcell. Chron., 395). Однако, ни в одном из источников, мы не видим четких свидетельств о насилии готов по отношению к местному населению, во время прохода варваров на запад через территорию Македонии (Zosim., V, 5, 5). Те же авторы сочинений (3осим, Клавдиан и т.д.), кто стремился в угоду Стилихону, создать негативный образ Алариха при упоминании этого готского передвижения, как уже говорилось, специально смешивали в тексте перипетии 395 года с событиями восстания готов в Греции в последующее время.

Но если нападения Алариха на Грецию в 395 году не было, то поход западной армии во главе с самим Стилихоном на Восток, который последовал практически сразу же после известий из Константинополя о заключении нового договора с готами, явно нуждается в объяснении. Обычно причиной такого восточного броска называют стремление Стилихона укрепить свою власть победой над готами [19, р. 327; 30, р. 269], восстановить моральный дух и боевые качества западной римской армии [13, с. 133], захватить территорию Востока $[11$, с. 76] и даже физически устранить Руфина (Claud. In Rufin., II, 139-168).

Тем не менее, все обозначенные предполагаемые причины, не дают нам полных ответов на многочисленные вопросы, связанные с походом римской армии на Восток. Заметим, что решить эту проблему чрезвычайно трудно из-за значительной тенденциозности дошедших до нас источников. В этой связи совет Й. Хьюджеса, о необходимости анализа действий Стилихона в ходе восточной компании, действительно может дать дополнительные аргументы для выяснения некоторых неясных аспектов указанных событий. Так, исходя из последовательности предпринятых Стилихоном шагов, можно прийти к выводу, что главной целью правителя Запада на Востоке являлся Аларих и его армия. При этом Й. Хьюджес предполагает, что такое внимание Стилихона к Алариху, могло быть вызвано прошлым предательством со стороны последнего [13, с. 132]. Однако в сложившейся ситуации вряд ли речь могла идти об отдаленных временах, ведь после смерти Феодосия І, внутриполитическая ситуация в империи резко изменилась и прошлые противоречия и конфликты уже в значительной степени потеряли свою актуальность. Теперь на первое место по своей значимости в государстве, выходили политические амбиции Стилихона, и особенно его курс на подчинение всей военной системы Римской империи личному контролю [31, р. 22]. Возможно, именно по этой причине, готы Алариха и были отпущены домой во Фракию, ведь конфликт готского рикса и Руфина гарантировал, что данные варвары, продолжат оставаться частью единой римской армии под командованием Стилихона. Однако Руфин вскоре начал тайно посылать Алариху сообщения о том, чтобы он не воспринимал всерьез лишение его должности, побуждая «его привести с собой варваров и все прочие имевшиеся у него силы», ведь «все ожидаемое им становится действительностью» (Zosim., V, 5, 4). Если же конфликт между префектом претория и Аларихом произошел, когда последний находился еще в Италии, что следует из приведенного текста, то он мог быть вызван Руфином специально, с целью вернуть федератов на Восток.

Однако, победа Руфина связанная с возвратом готов, вынуждала предпринять ответные действия со стороны могущественного правителя Запада. Тем более что политика Руфина, все более начинала вступать в противоречие с далеко идущими амбициями Стилихона. Вот почему, особое беспокойство у него, вызвал заключенный Руфином новый договор с федератами, разрешающий их новое расселение в стратегически важном для Запада Иллирике. Следовательно, главной угрозой Стилихону и 
основной причиной его похода на Восток, скорее всего, стал союз Руфина и Алариха, который абсолютно не входил в планы могущественного опекуна. По всей вероятности, Стилихон поставил себе цель разорвать данный договор, а Алариха вернуть под свое командование. По нашему мнению, действия, которые начал предпринимать Стилихон на Востоке, более всего свидетельствуют в пользу именно такой стратегии правителя Западной Римской империи. Рассмотрим их подробнее.

Во-первых, была предпринята беспрецедентная пропагандистская компания по обвинению Руфина в «заговоре против государства» (Zosim., V, 5, 3). Сущность такого оскорбительного навета, выдержанного в лучших традициях идеологической войны, лучше всего отразил Клавдиан, заклеймив Руфина в своих поэтических строках, что «сколько стоило крови создать и упрочить державу, сколько вождей положили труды на ее утвержденье, сколько лет стояла она под римскою властью, все один погубил изменник в мгновение ока!» (Claud. In Rufin., II, 50-53). Разумеется, Руфин, как и любой представитель позднеримского времени, занимающий государственный пост высокого уровня, не относился к категории порядочных и добродетельных людей. Для того чтобы выжить ему не раз приходилось идти на обман, заниматься тайными интригами или совершать откровенные преступления. Даже вторжение гуннов в римские провинции в 395 году, возможно, было намеренно допущено Руфином, так как улучшало его отношения с кочевниками и ставило Стилихона в безвыходную ситуацию, требующую от командующего однозначного возврата восточной армии в Константинополь [15, с. 553-567]. Все это действительно давало повод для многочисленных недругов в обвинении префекта претория Востока в предательстве и государственной измене. Однако, то обстоятельство, что в подобной идеологической войне нередко к реальным фактам добавлялась значительная порция откровенной лжи, которая в значительной степени искажала историческую картину, не позволяет нам некритически подходить к подобного рода информации.

Во-вторых, похоже, что Стилихон, в этот непростой период решил назначить Гайну на высокую должность магистра Фракии (Zosim., V, 13, 1, 14, 1). Разумеется, это утверждение спорно, тем более что у Марцеллина Комита на момент убийства Руфина, Гайна упоминается только в качестве комита (Marcell. Chron., 395). Тем не менее, вышеобозначенный текст Зосима, недвусмысленно намекает на наличие поста регионального магистра у готского командира. При этом назначение Гайны на магистерскую должность после гибели Руфина [18, р. 155, 169], не согласуется с приостановкой его продвижения по службе при Евтропии [10, с. 107-112]. Более того, то обстоятельство, что Гайна не был повышен в чине при могущественном евнухе [14, с. 85], по крайней мере, до трагических событий восстания Трибигильда, подтверждают его личные жалобы на Евтропия (Zosim., V, 13, 1, 17,4). Следовательно, должность магистра Фракии именитый гот, действительно мог получить только от Стилихона. По нашему мнению, данное противоречие является чрезвычайно важным для понимания всей сложившейся ситуации в империи на момент заговора против Руфина. Не исключено, что Гайна, отправляясь в Константинополь, действительно являлся только комитом - командиром воинских подразделений, возвращающихся на Восток, ведь это хорошо согласуется с известием, что Стилихон еще на этапе отправки войск на Восток «назначил их командиром Гайну» (Zosim., V, 7, 4; lord. Get., 176). Тогда должность магистра Фракии могла быть обещана ему Стилихоном в качестве награды за ликвидацию Руфина. Возможно, это был первый шаг могущественного правителя Запада, на пути к возвращению готов-федератов Алариха обратно в пограничные придунайские провинции, но только под командование уже не изменника Алариха, а доказавшего свою верность Гайны.

В-третьих, подробности военной компании Стилихона в 395 году, однозначно указывают на не совсем типичную войну, которую он вел на Востоке, якобы с напавшими на римлян варварами. Особенно обращает на себя внимание нежелание Стилихона рисковать жизнями своих солдат и активно воевать, по сути дела с такой же, как и у него, римской армией. Создается впечатление, что Стилихон не хотел уничтожать готов, а желал только добиться возвращения большей части варваров обратно под свое командование. При этом, похоже, что главной задачей военного похода Стилихона являлось оперативное перекрытие варварам всех путей, ведущих на территорию диоцеза Иллирик. Видимо данным обстоятельством была обусловлена спешка с выступлением в восточный поход, которая отчетливо прослеживается по срочному заключению Стилихоном договора с франками на Рейне [23, р. 183]. Видимо все это было не зря, так как Стилихон успел развернуть не дошедшего до Иллирика Алариха на юг в Фессалию, где последнему в вскоре пришлось укрепляться и поджидать западную армию [3, с. 202]. Положение для готов осложнилось еще и с тем, что видимо из-за нарушения маршрута передвижения федератов, прекратились (или не были организованы вообще) поставки продовольствия, и готам пришлось силой забирать продукты у местного населения, которое стало отчаянно сопротивляться. В устье реки Пеней на горе Пинд в Фессалии, местные жители даже устроили готам засаду, напав на них во время переправы через реку, заперев потом варваров в долине и затруднив им грабеж окрестных населенных пунктов (Socr., VII, 10). Возможно, именно здесь Стилихон и настиг готов Алариха [13, с. 133-134], однако к решающей битве это почему-то не привело. Окружив готов и наладив поставки продовольствия своей армии, опять же, за счет 
местного населения, Стилихон отказался от решающего сражения и не стал нападать на готов (Claud. In Rufin., II, 170-250) [11, с. 78]. Такая тактика главнокомандующего косвенно подтверждает мнение, что главной целью всей восточной компании Стилихона было не уничтожение готов Алариха, а разрыв договора варваров с Руфином и возвращение федератов под свое командование. Видимо это был наиболее действенный способ заставить Константинополь принять его притязание на главенство над всей Римской империей [21, р. 60]. Кроме того, не будем забывать, что в Фессалии Стилихон окружил не варваров, напавших на империю, а именно римскую армию, во главе которой находился официально назначенный Аркадием, иллирийский главнокомандующий Аларих [3, с. 202]. Военные действия двух римских армий между собой, несмотря на варварский состав одной из них, не могли принести ничего хорошего для дальнейшей карьеры обоим командующим. Негативные последствия такого побоища, легко могли использовать в свою пользу их многочисленные недоброжелатели.

Неизвестно сколько бы продолжалось данное противостояние, если бы ситуацию радикально не разрешил Руфин. По словам Клавдиана он обратился к Аркадию с гневным обличением Стилихона, который, по его словам, «два мировых полушарья хочет подмять под себя», и не выносит «равного рядом», а теперь же хочет гибели Руфина, хотя сам незаконно вторгся в земли брата. Поэтому пусть Стилихон «отойдет из Иллирика, пусть восточное войско он вернет на восток, пусть брат поделится с братом» (Claud. In Rufin., II, 144-168). Нетрудно догадаться какая была реакция Стилихона, когда он получил приказ Аркадия отправить восточную армию в Константинополь, а самому вернуться домой в Италию. С одной стороны, Стилихон обязан был выполнить приказ императора, что он, разумеется, и сделал. Однако, с другой стороны, сложившаяся ситуация, дала ему прекрасный повод для обвинения Руфина в государственной измене и в итоге окончательно способствовала успешному устранению опасного врага.

Об эффективности такой пропаганды, свидетельствует решающая роль, которую сыграла во всех этих событиях римская армия в целом [5, с. 73]. Дело в том, что только безоговорочная поддержка армии в этих новых изменившихся условиях, смогла допустить возможность организации заговора по физическому устранению Руфина. По-видимому, на каком-то этапе, его насильственная смерть стала представляться Стилихону, единственным выходом из создавшейся ситуации. С этой целью «Стилихон организовал солдат для выполнения своей миссии, назначив их командиром Гайну и посвятив последнего в свой заговор против Руфина. В соответствии с планом, когда солдаты были на подходе к Константинополю, Гайна раньше прочих выдвинулся вперед, чтобы сообщить императору Аркадию об их прибытии» и необходимости «лично встретить солдат». Однако, когда это случилось и воины «распростерлись ниц для получения красивых славословий от императора, по сигналу Гайны они вскочили, окружили Руфина и поразили его своими мечами. Один отсек его правую руку, другой - левую, а кто-то еще обезглавил тело». В дальнейшем солдаты носили кисти рук Руфина «вокруг всего города, требуя от всех жителей, чтобы они заплатили деньги за свое избавление от тирана» (Zosim., V, 7, 3-6). Любопытно, но, несмотря на этот, достаточно определенный рассказ Зосима, большинство других авторов при описании данных событий, почему-то прямо не говорят, что солдаты убили Руфина по прямому приказанию Стилихона (Claud. In Rufin., II, 228-527; Socr., VI, 1; Soz., VIII, 1; Marcell. Chron., 395). Филосторгий же, подтверждает версию Зосима о том, что солдаты «сделали это отчасти по наущению Стилихона», правда, добавляя в тексте еще и довольно оригинальную информацию о насмешках Руфина над воинами, что якобы также сыграло свою роковую роль в судьбе префекта претория Востока (Philost., XI, 3). Стоит еще добавить, что «благодаря этому человеку [Стилихону]», был убит не только Руфин, но и «побеждена» его «личная охрана из гуннов» (Chron. Gall., 1, 650).

Недосказанность и умолчание вышеупомянутых источников, являются причиной отсутствия единой точки зрения на трагедию гибели властителя восточной части Римской империи. При этом сложнее всего ответить на вопрос: был ли Стилихон лично причастен к организации убийства Руфина или нет? Одни исследователи соглашаются с версией Зосима, что приказ убить префекта претория Востока был отдан непосредственно Стилихоном [20, р. $113 ; 22$, р. $154-155 ; 27$, р. $113 ; 24$, p. 195; 9, с. 140; 3, с. 203; 6, с. 54; 1, с. 54-55]. При этом отдельные авторы иногда расширяют круг участников заговора, ссылаясь на сообщение Зосима о Евтропии, «который был коллегой Стилихона во всех его замыслах против Руфина» (Zosim., V, 8, 1) [11, с. 79; 2, с. 43]. Другие ученые высказывают сомнения в причастности Стилихона к убийству Руфина [21, р. 90-91;13, с. 139-140], и даже предлагают необычные версии смерти префекта претория Востока, например, по причине заговора Гайны и Евтропия [21, р. 146-148]. Некоторые же исследователи вообще стараются избегать данной дискуссии при описании этих событий $[4$, с. $467 ; 7$, с. 37; 12, с. 275-277].

По нашему мнению, чтобы разобраться с данным вопросом, необходимо обратить внимание на ряд очень важных обстоятельств. Так, явная безнаказанность Гайны за совершенное преступление, однозначно свидетельствует в пользу участия в заговоре еще и Евтропия [2, с. 43]. То, что это обстоятельство полностью соответствует сообщению Зосима (Zosim., V, 8, 1), безусловно, повышает доверие к данному источнику. 
Далее заметим, что стремящийся к узурпации власти на Востоке Гайна, мог легко предпринять шаги в данном направлении, сразу же после убийства Руфина, но почему-то, этого не сделал. Очевидно, что в момент появления его в Константинополе, у него отсутствовал такой план [18, р. 154]. Следовательно, в это время Гайна еще не ориентировался на собственную цель, а лишь выполнял чужие приказы, являясь простым исполнителем воли Стилихона, которому он непосредственно подчинялся. Ситуация хорошо согласуется со словами Зосима о Стилихоне, как о главном организаторе заговора против Руфина. участниками которого были также Гайна и Евтропий (Zosim., V, 7, 3-6, 8, 1). Однако Гайна, как главный исполнитель убийства Руфина, почему-то, не смог сделать карьеры при Евтропии. Если всемогущий евнух после устранения Руфина резко возвысился, став консулом и патрикием (Zosim., V, 17,4), то Гайна не был удостоен ни особым почетом, ни ценными дарами, что и вызвало его возмущение и недовольство (Zosim., V, 13, $1,17,4)$. Все это свидетельствует о том, что Евтропий не был обязан Гайне и поэтому не стремился помогать именитому готу, продвигаться по служебной лестнице [10, с. 108]. Похоже, что все участники заговора против Руфина, были связаны друг с другом лишь опосредованно, через Стилихона. В этой связи, нам представляется ошибочным считать, что Гайна убил Руфина, ориентируясь исключительно на свои амбициозные планы, а Стилихон, зная о властолюбии своего командира, специально отправил его в Константинополь, основываясь лишь на предположении, что тот возможно, когда-нибудь, все же свергнет префекта претория Востока [13, с. 137]. И дело здесь даже не в расчете Стилихона на гипотетический политический хаос на Востоке, который якобы должен был здесь начаться в ходе демонстрации бессилия власти против бесчинства готов и тем более после свержения Руфина. Гайна не похож на человека, который презирает холодный расчет и действует исключительно под влиянием эмоций. Скорее всего, наоборот. Поэтому, не имея достаточно веских гарантий своей безопасности за содеянное преступление, вряд ли Гайна решился бы на публичное совершение убийства высшего римского должностного лица. В свою очередь, Стилихон мог послать в Константинополь только проверенного человека, в верности которого не сомневался, ведь он, в конечном итоге, должен был возглавить крупные подразделения армии Востока. В этом случае Гайна, своим подчинением западному римскому командованию и лично Стилихону, обеспечил бы установление контроля последнего над всеми вооруженными силами империи. Вероятно, в этом и заключалась главная цель отправки восточной армии в Константинополь и операции по устранению Руфина. Одобрение на такое изменение соотношений сил в империи, по-видимому, было получено и от Евтропия, который на этом этапе заговора, был согласен на все, лишь бы избавиться от Руфина. Не вызывает сомнений, что при удачном стечении обстоятельств, осуществление командования над всеми западными и восточными подразделениями армии, привело бы Стилихона к его главной цели - главенству над всей империей.

Таким образом, одной из главных причин конфликта римлян с находившимися в данный момент в Италии готами, явилось неожиданное для варваров известие о жестоком разорении гуннами их домов во Фракии. Все это вызвало необходимость пересмотра гото-римского договора и требование варваров предоставить им новые, более безопасные территории для расселения.

Однако, заключенный Руфином новый договор с Аларихом, разрешающий расселение готов в стратегически важном для Запада Иллирике, вызвал сильное раздражение у Стилихона, который срочно отправился походом против готов. Именно оправдание данного вторжения и попытка скрыть его истинные причины, привели к появлению в источниках ужасов готского «восстания», которое на самом деле не выходило за рамки насильственного отъема варварами продовольствия у местного населения. На самом деле основной причиной похода Стилихона на Восток, скорее всего, стал союз Руфина и Алариха, который абсолютно не входил в планы могущественного опекуна. Скорее всего, Стилихон поставил себе цель разорвать данный договор, а Алариха вернуть под свое командование. Видимо это был наиболее действенный способ заставить Константинополь принять его притязание на главенство над всей Римской империей. Однако вскоре планы могущественного правителя Запада пришлось серьезным образом корректировать. Приказ Аркадия Стилихону покинуть территорию Востока и вернуть в Константинополь восточную армию, за которым однозначно стоял Руфин, поставил Стилихона перед непростым решением. По-видимому, только насильственная смерть Руфина стала представляться Стилихону, единственным выходом из создавшейся ситуации. С этой целью правитель Запада организовал заговор, в который были вовлечены непосредственный исполнитель готский командир Гайна и препозит священной опочивальни евнух Евтропий. В случае успеха Стилихон обещал Гайне должность регионального магистра Фракии, где он должен был заменив Алариха, возглавить возвращенных обратно на свои земли готов. Евтропий же освободившись от Руфина, занимал его место при императоре. Но самые большие привилегии от устранения Руфина, разумеется, получал Стилихон. Очевидно, было предусмотрено, что Гайна своим подчинением западному римскому командованию и лично Стилихону, должен был обеспечить установление контроля последнего над всеми вооруженными силами империи, несмотря на их разделение на западную и восточную армии. В случае успеха, это бы привело Стилихона к его главной цели - главенству над всей империей. 


\section{ЛИТЕРАТУРА}

1. Богданов Д.Е. Военные компании «последнего защитника Рима» Флавия Стилихона // Научные ведомости БелГУ. Серия История, Политология. 2015. №7(204). Вып. 34. С. 53-57.

2. Богданов Д.Е. Борьба Западного и Восточного дворов Римской империи в конце IV века // Научные ведомости БелГУ. Сер. История. Политология. 2017. №22(271). Вып. 44. С. 41-45.

3. Вольфрам Х. 2003. СПб.: Ювента, 2003.656 с.

4. Голдсуорти А. Падение Запада. Медленная смерть Римской империи. М.: АСТ, 2014. 733 с.

5. Козлов А.С. Борьба между политической оппозицией и правительством Византии в 395-399 гг. // Античная древность и средние века. Свердловск, 1976. Вып. 13. С. 68-82.

6. Коньков Д.С. Готы на территории Римской империи: трансформация этно-потестарной идентичности. Северск: Изд-во СТИ НИЯУ МИФИ, 2011. 151 с.

7. Коптелов Б.В. Политическая борьба в Римской империи конца IV в. н.э. и ее отражение в поэзии Клавдиана // Вестник МГГУ им. М.А.Шолохова. Серия История и Политология. 2013. №2. С. 33-42.

8. Кузнецов А.М. Воинский этикет в армии Древнего Рима //0бщество: философия, история, культура. 2017. №1. С. 135-139.

9. Кулаковский Ю.А. История Византии. 395-594 гг. СПб.: Алетейя, 1996. Т. І. 445 с.

10. Пржигодзкая 0.В. К вопросу о мятежах в Римской империи в IV в.: Восстание гота Гайны в Константинополе в $399-400$ гг. // Вестник СанктПетербургского университета. 2013. Сер.2. Вып. 1. С. 107-112.

11. Сиротенко В.Т. Борьба Западной Римской империи и Византии за префектуру Иллирик в 395-425 гг. и ее последствия // Античная древность и средние века. Свердловск, 1972. Вып. 8. С. 73-88.

12. Хизер П. Великие завоевания варваров. Падение Рима и рождение Европы. М.: Центрполиграф, 2016. 830 с.

13. Хьюджес Й. Стилихон. Вандал, который спас Рим. М.: Изд-во «Клио», 2017. 352 с.

14. Чекалова А.А. Варварский элемент в Византии (IV-V века) // Цивилизация и варварство: механизмы, инструменты и субъекты взаимодействия. М.: Аквилон, 2014. Вып. III. С. 75-102.

15. Ярцев С.В., Зубарев В.Г. 0 причинах нападения гуннов Северного Причерноморья на Римскую империю в 395 г. // Материалы по археологии и истории античного и средневекового Причерноморья. 2020. №12. С. 553-567.

16. Arce J. Alarico (365/370-410 A.D.) La integración frustrada. Madrid: Marcial Pons Historia, 2018. 180 p.

17. Boin D. Alaric the Goth: An Outsider's History of the Fall of Rome. New York: W.W. Norton \& Company, 2020. 272 p.

18. Burns T. Barbarians within the gates of Rome: a study of Roman military policy and the barbarians, ca. 375-425 A.D. Bloomington: Indiana University Press, 1994. $417 \mathrm{p}$.

19. Burns T. Rome and the Barbarians, 100 B.C. - A.D. 400 (Ancient Society and History). Baltimore: Johns Hopkins University Press, 2003.461 p.

20. Bury J.B. History of the later Roman Empire: from the death of Theodosius I to the death of Justinian (A.D. 395 to A.D. 565). London: Macmillan, 1923. 471 p.

21. Cameron A. Claudian: Poetry and Propaganda at the Court of Honorius. Oxford: Clarendon press, 1970. 508 p.

22. Demougeot E. De l'unité à la division de l'empire romain, 395-410. Paris: Adrien-Maisonneuve, 1951. 618 p.

23. Elton H. Warfare in Roman Europe AD 350-425. 0xford: Clarendon Press, 1996. 312 p.

24. Halsall G. Barbarian Migrations and the Roman West 376-568. Cambridge: Cambridge University Press, 2007. 591 p.

25. Heather P.J. Goths and Romans, 332-489. 0xford: Clarendon Press, 1991. 378 p.

26. Heather P.J. The Goths (The Peoples of Europe). Oxford; Cambridge: Wiley-Blackwell, 1996. 358 p.

27. Jones A.H.M. The Later Roman Empire 284-602: A Social, Economic and Administrative Survey. Oxford: Basil Blackwell, 1964. Vol. I. 522 p.

28. Jones A.H.M. The Decline of the Ancient World. London; New York: Longman, 1966. 422 p.

29. Kulikowski M. Rome's Gothic Wars: From the Third Century to Alaric (Key Conflicts of Classical Antiquity). Baltimore: Cambridge University Press, 2007. 225 p.

30. Matthews J. Western Aristocracies and Imperial Court A.D. 364-425. Oxford: Clarendon Press, 1975. 427 p.

31. O'Flynn J. Generalissimos of the Western Roman Empire. Alberta: The University of Alberta Press, 1983. $250 \mathrm{p}$.

32. Wolfram H. The Roman Empire and its Germanic Peoples. Berkeley: University of California Press, 1997. 381 p.

(c) Ярцев Сергей Владимирович (s-yartsev@yandex.ru). 